\section{The role of organic urine sediment analysis in the monitoring of renal disease}

\section{ABSTRACT}

Cytological analysis of urine sediment is an integral part of urine analysis and a useful, cost-effective diagnostic tool for all routine clinical examinations, which can sometimes be overlooked in veterinary practice. Proper handling and timely urine sample analysis are essential for valid microscopic analysis. Microscopic urinary sediment testing is usually carried out with stained or unstained specimen. A common urine may contain a small number of cells (erythrocytes and leukocytes, epithelial cells) of several crystals, spermatozoids (male animals). In contrast, a large number of cells or casts, the presence of unusual types of crystals, neoplastic cells, parasites, and microorganisms refer to abnormal findings and thus require a specialized diagnostic approach. Correct identification of organic components of the urinary sediment are crucial for accurate and timely diagnosis of kidney disorders. Laboratory experts should be trained to properly identify and classify organic components of the urinary tract.

Keywords: Urinary sediment, microscopic evaluation, pre-analytic and analytical factors of urine analysis

\section{INTRODUCTION}

Urine is a body fluid that has the potential to answer many of the body's secrets. Urine processing, as the first biological material, for the purpose of diagnostic information goes far into the past and is the source of scientific knowledge about the human and animal body. The first beginnings of microscopy were already recorded in the first half of the 17th century (Sikirica et. al., 2002). Cytological examination of urine includes urine sediment analysis that may be spontaneously urinated, catheterized or obtained by percutaneous puncture of vezicae urinariae. (Chew and Di Bartola, 2004). Urine cytology is useful in the detection and diagnosis of various benign diseases and conditions such as infections of different etiologies, and in distinguishing hematuria from the upper and/or lower urinary tract. In addition, it is useful in detecting inflammation in the bladder and kidney (Caleffi and Lippi, 2005; Bottini et.el., 2005; Bakan et. al., 2016; Alatzas et.al., 2012; Sikirica et. al., 2002). In human medicine cytology can predict the rejection of transplants in more than $64 \%$ of patients with renal transplantation prior to the clinically recognizable organ rejection (Eggensperger et. al., 1988).

Indications for cytological examination of the urine are: screening of asymptomatic patients exposed to carcinogens, triage of symptomatic patients, detection of non-neoplastic, premalignant and malignant lesions, metastatic tumors, lesions that cannot be detected by cystoscopy or biopsy, and monitoring of therapy (Ostović, 2015). First of all, an identification of the urinary sediment is crucial for the accuracy and timely diagnosis of renal disorders (Caleffi and Lippi, 2015).

\section{How to cite this article}

Katica, M., Hassan-Ahmed, N., Salkić, A., Mukača, A., Bašić, A., Dervišević, E. (2019) The role of organic urine sediment analysis in the monitoring of renal disease. $J$ Adv VetBio Sci Tech. 4(1): 40-50. DOI: http://doi.org/10.31797/vetbio.524209

\section{Review}

Muhamed Katica ${ }^{1}$ Nasreldin Hassan Ahmed ${ }^{2}$ Alen Salkić ${ }^{3}$ Adis Mukača ${ }^{4}$ Ajdin Bašić ${ }^{5}$ Emina Dervišević ${ }^{6}$

\footnotetext{
${ }^{1}$ Department of pathological physiology, Veterinary faculty, University of Sarajevo, Bosnia and Herzegovina ORCID: 0000-0002-8184-0065

${ }^{2}$ Emergency medicine clinic, University Clinical center Sarajevo, University of Sarajevo, Bosnia and Herzegovina, ORCID: 0000-0002-5728-7052

${ }^{3}$ The owner of the veterinary station, Dr. Salkić d.o.o. - Travnik, Bosnia and Herzegovina, ORCID: 0000-0002-5728-7052

${ }^{4}$ Cantonal Veterinary Inspector, ZenicaDoboj Canton, Bosnia and Herzegovina, ORCID: 0000-0002-5728-7052

${ }^{5}$ Director of Veterinary Station Bugojno, Bosnia and Herzegovina, ORCID: 0000-0002-5728-7052

${ }^{6}$ Department of Forensic Medicine, Faculty of Medicine, University of Sarajevo, Bosnia and Herzegovina ORCID: 0000-0002-5728-7052
}

Correspondence

Dr.sc. Muhamed Katica, Docent Department of pathological physiology Veterinary faculty, University of Sarajevo Zmaja od Bosne 90 / 71000 Sarajevo

Bosna i Hercegovina ++38733729155

E-mail: muhamed.katica@vfs.unsa.ba

Submission: 08-02-2019

Accepted: 26-04-2019

Online published: 28-04-2019

This work is licensed under a Creative Commons Attribution 4.0 International License (c) (1) 
Credit for the scientific development in research of urinary corpuscular elements over the past 10 years goes to the automated analyzers or automated microscopy, or more specifically, to the flow cytometry and digital imaging systems (Anderlini et al., 2015; Bakan et al., 2016; Bogaert et al., 2016; Oyaert, and Delanghe, 2018). However, the total accuracy of these instruments in identifying (erythrocytes, leukocytes, epithelial cells, casts) is questionable. The gold standard for the study of urinary sediment elements, or the best identification, is still based on traditional, phasecontrast microscopic, manual analysis with low and high power magnification (Bogaert etal., 2016; Caleffi and Lippi, 2015; European Confederation of Laboratory Medicine, 2000; Clinical and Laboratory Standard Institute, 2009).

This review article focuses on pre-analytic and analytical factors that influence the urinary sediment identification, as well as on the normally expected sediment elements and the clinically relevant interpretation of abnormal findings of urinary sediment in some renal diseases.

\section{Pre-analitic and analytical factors affecting urinary sediment identification}

Different methods of collecting urine (medium discharge, catheterization or percutaneous cystocentesis) all have advantages and disadvantages, and the clinician must decide on the best method of urine collection, depending on the medical background of the animal disease and specific cases of urine analysis (Alatzas et al., 2012). Several pre-analytic issues related to collecting, transporting, and storing of the samples present a serious challenge to the quality of urine analysis. (Caleffi et al., 2010; Fogazzi, 2010). The collection method of urine sample can affect the results of the analysis. Standardized urine volumes should be obtained each time, to allow for comparisons of urine sediment and comparisons to the subsequent samples (Reine and Langston, 2005).

During the analytical phase, alkaline urine favors the lysis of cellular elements. Such adverse environment causes the imprecise identification and classification of urinary sediment elements. In addition, there is a large amount of amorphous phosphates and crystals. (Fogazzi, 2010; Caleffi and Lippi, 2015).

It is very important to be careful when transporting and storing samples. Storage of urine samples for more than 3 hours can cause lysis and degeneration of urinary sediment elements (Manoni et al., 2008). The sample should be stored at $+4{ }^{\circ} \mathrm{C}$. Such storage should be as short as possible, due to the tendency of phosphate and urate salts to settle down. They often hide diagnostically significant organic elements of the urine sediment. The sample can be stored at the room temperature of $+20{ }^{\circ} \mathrm{C}$, if the analysis takes place within 30 minutes, becuase lysis of cellular elements after that time (Sikirica et. al., 2002). There is a report confirming the conservation of up to 90 days of organic components of urine sediment, if conserved with $3 \%$ sodium phosphateformaldehyde prior to the storage (Bottini et. al., 2005)

\section{Volume of urine for centrifugation}

The volume of urine for centrifugation must be precisely defined and is usually in the range between 5 - $15 \mathrm{ml}$ (Sikirica et al., 2002). Since it always has to be equal, the use of single-layer polystyrene tubes with a conical bottom is recommended, marked with chosen volumes of urine for centrifugation. Each change in the volume of urine taken for analysis must be indicated for accurate quantification of cellular elements. To minimize mechanical damage to the cells and simultaneously quantitatively sediment, the recommended centrifugation time is 5 minutes $2500-3000 \mathrm{rpm}$ (Sikirica et al., 2002). The next step is to remove urine supernatants from the upper area. The precipitate is mixed with the rest of the urine (about $0.5 \mathrm{ml}$ ) and using a pipette, a drop is placed on a glass slide and covered with a glass cover slip (Alatzas et al., 2012).

\section{Supravital staining of urine sediment}

To obtain a stained preparation, the precipitate is mixed with a stain, for example, New Methylene Blue (Alatzas et al., 2012). 10\% of stain of the urine sediment volume is added to the urine sediment, for example, $0,5 \mathrm{ml}$ of urine sediment and 50 microliters of stain. In order for the sediment to come into contact with the stain, it is necessary to 
stir the test tube lightly and allow it to stand for 510 minutes. Coloring starts right away, where color intensity is increasing particularly in the first five minutes. (Kouri et al., 2000; Sikirica et al., 2002; Chew and Di Bartola, 2004).

To prepare the preparations fixated in methanol, a drop of the precipitated urine is placed on a glass slide, dried and fixed, and later stained using conventional coloring procedures (e.g., Diff Quick staining technique or another staining procedure) (Swenson et al., 2004; Alatzas et al., 2012).

Microscopic treatment of the urine sediment obtained in such a way is the most complex part of the analytical procedure because it requires education, long-term exercise and a good optical instrument.

\section{Hematuria}

Hematuria may be a consequence of a minor or an abundant bleeding, caused by lesions of distal or proximal parts of the urinary tract, or the consequence of a systemic coagulopathy (Figure 1). In dogs and cats, hematuria is most commonly a consequence of the lower urinary system disease (Adamama-Moraitou, 2017; White et al., 2008; Forrester, 2004). It may also be caused by infections, inflammatory diseases, stones, trauma, haematological disorders, prostate enlargement and tumors (Kardum-Skelin, 2004; Sharma et al., 2009; Nakamura et al., 2009; Knežević et al., 2011).

Cytologic analysis of the urinary sediment can point to some diseases associated with erythrocytosis such as lithiasis, glomerulonephritis, or it can help diagnose bladder inflammation (Ostović, 2015).

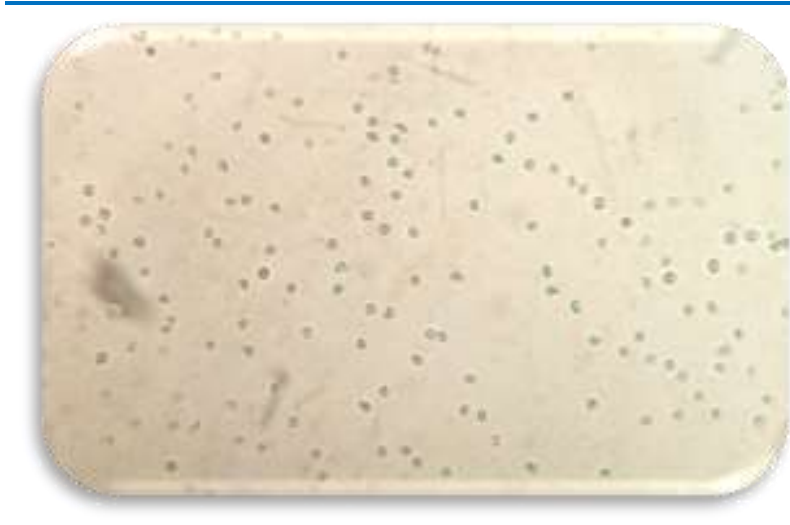

Figure 1. A multitude of erythrocytes in the urinary sediment (macrohematuria), in an unstained smear, 100x magnification.
The presence of $80 \%$ and more of the dysmorphic erythrocytes during urinary sediment analysis in presented microscopic fields (Figure. 2) indicates bleeding from the upper part of the urinary tract, while $80 \%$ and more of the smooth (normal) erythrocytes in presented microscopic fields indicate bleeding from the lower part of the urinary tract (Kardum-Skelin, 2004; Knežević et al., 2011).

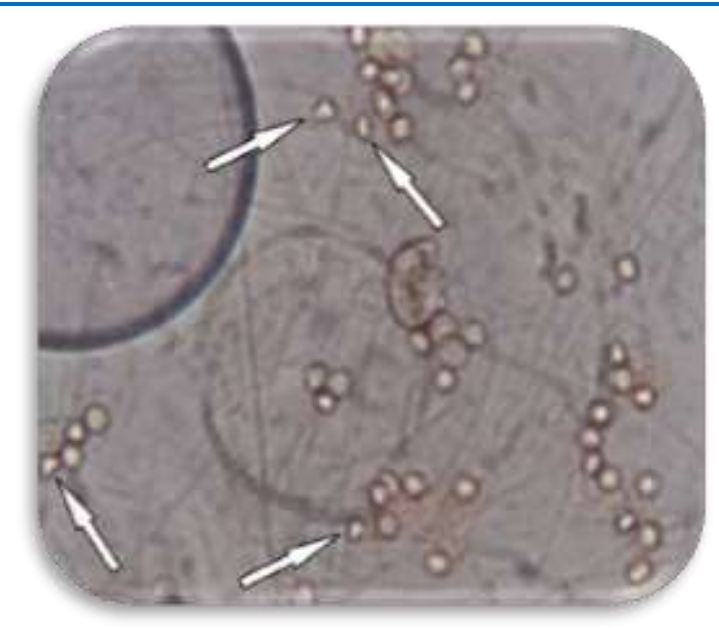

Figure 2. Dysmorphic erythrocytes (white arrows), in an unstained smear 400x magnification

Renal causes of hematuria include glomerular diseases and non-glomerular states including neoplasia, nephroliths, trauma, pielonephritis and idiopathic kidney hematuria (Adamama-Moraitou, 2017; Forrester, 2004). Hematuria is not a pronounced characteristic of glomerular disease in cats and dogs (Nash et al. 1979, Cook and Cowgill, 1996). A normal urine sediment should contain very little erythrocytes, depending on the way the urine was obtained. The threshold of microscopic hematuria in human medicine is 3 erythrocytes/hpf, as established by the American Urological Association (Adamama-Moraitou et al., 2017; Grossfeld et al. 2001). The limit value of microscopic hematuria in veterinary medicine is set to $\geq 8$ erythrocyte/hpf in fresh urine, to $\geq 5$ for the urine samples obtained by catheterization, and to $\geq 3$ erythrocyte/hpf for samples collected by cystocentesis (Chew and Di Bartol, 2004). Depending on the extent of trauma during the collection of urine samples, especially in repeated cystocenteses, it is possible to find up to $\geq 50$ erythrocyte/hpf (Chewet al., 2011; Chew and Di Bartola, 2004). 
The urine sediment content is affected by its specific gravity. For example, 10 erythrocyte/hpf in a urine sample with a specific gravity of 1.014 may be comparable to 20 to 30 erythrocyte/hpf in a urine sample with a specific gravity of 1.050 (Chew and Di Bartola, 2004). Erythrocytes in highly concentrated urine will be smaller in diameter, while in a very diluted one they will cause swelling of the erythrocytes (Chew and Di Bartola, 2004).

\section{Leukocyturia}

An increased number of leukocytes (pyuria) indicates inflammatory processes or contamination of the urinary tract. A huge amount of leukocytes, primarily neutrophils, indicates the presence of bacteria, for example of pyelonephritis (Jerkić and Božić, 2012). Leukocytes in an unstained and stained smear of the urinary sediment are greater by 150-200\% than erythrocytes (Figure 3.) (Alatzas et al., 2012; Chew and Di Bartola, 2004).

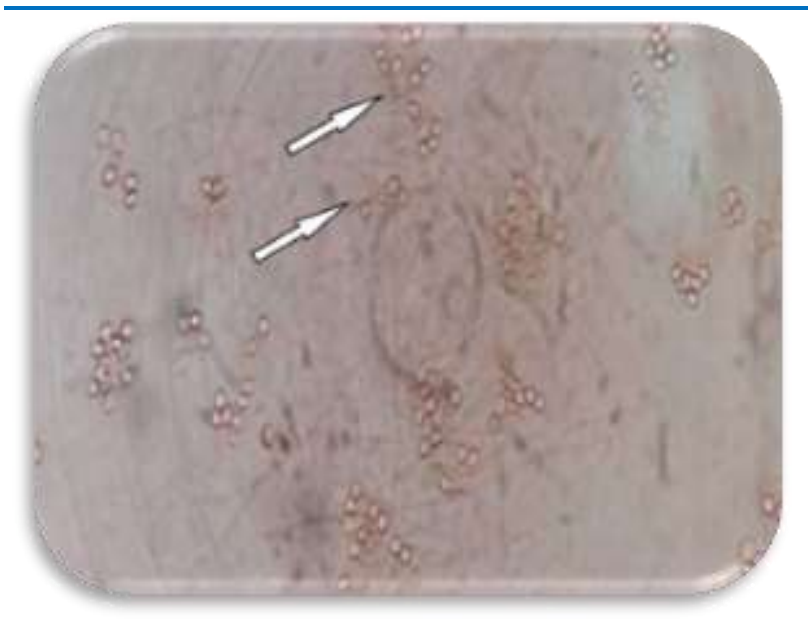

Figure 3. Leukocytes in an unstained smear (white arrow) of the urinary sediment, 100x maginification

Lymphocytes and monocytes are difficult to distinguish from small kidney epithelial cells in the urinary sediment (Chew and Di Bartola, 2004). Leukocytes follow the same criteria when declaring leukocyturia; urine obtained spontaneously $\geq 8$ leukocytes/hpf, after catheterisation $\geq 5$, and $\geq 3$ leukocytes/hpf for samples collected by cystocentesis (Chew and Di Bartola, 2004; Di Bartola et al., 2011; Alatzas et al., 2011) Leukocyte groups often occur with bacterial infections of the urinary system even when bacteria are not visible. Careful examination of the space in between piled neutrophils often helps with recognizing bacteria (Chew and Di Bartola, 2004).

\section{Cylindruria}

The casts are important components of the urine sediment as they can be associated with a number of renal disorders whose diagnosis may also be proper urine identification (Rizzi et. al, 2017; Caleffi and Lippi, 2015; Chew and Di Bartola, 2004). It is also necessary to know that urine sampling after intense physical activity can cause, among other things, severe cylindruria. It is not advisable to examine too alkaline urine because such an environment prevents the formation of casts and favors the lysis of other cellular elements. Additional conditions that may violate the exact identification and classification of casts include: contamination of the sample with genital secretions, the presence of large amounts of amorphous phosphates and crystals, as well as the urine of low urine specific gravity (Fogazzi, 2010; Caleffi and Lippi, 2015). The cylinders faithfully depict the inner tubular lumen of the ascending parts of the Henle loop, the distal tubules or the kidney collection canals, where they are created. The narrowest diameters have those originating from the Henle loop, while the widest ones are those coming from the collection canals (Rizzi et al., 2017). They are made out of a specific matrix, i.e. Tamm-Horsfall glycoprotein (THG), with most commonly added epithelial cells and/or blood corpuscles (erythrocytes, leukocytes). It is of the utmost importance to note that the casts are formed in the kidney tubules, and all the elements embedded in the cast matrix come from the kidneys, so being of great diagnostic importance (Fogazzi, 2010; Caleffi and Lippi, 2015).

\section{Classification and clinical significance of casts}

Numerous literary citations describe a wide range of kidney casts. For didactic and educational reasons, they are differentiated according to the size and morphological characteristics that depend on the types of embedded cells (Table 1.) (Chew et al., 2011; Rizzi et al., 2017; Fogazzi, 2010; Caleffi and Lippi 2015; Chew and Di Bartola, 2004; Alatzas et al., 2012). Sikrica et al. (2002) note that there are different levels of microscopic classifiaction in the clinical treatment of urine. According to this classification, the left column (Type) of Table 1. shows a baseline level, while the right column (Subtype) of Table 1. shows an additional level of 
microscopic classification in the clinical treatment of urine.

Table 1. Classification of casts.

\begin{tabular}{|c|c|}
\hline Type & Subtype \\
\hline Hyaline & - \\
\hline \multirow{2}{*}{ Granular } & Finely granular \\
\hline & Coarsely granular \\
\hline Waxy & - \\
\hline Broad cast & - \\
\hline Fatty & - \\
\hline \multirow[t]{3}{*}{ Cellular } & Leukocytic \\
\hline & Erythrocytic \\
\hline & Epithelial \\
\hline \multirow[t]{5}{*}{ Mixed } & Hyaline-granular \\
\hline & Granular-celular \\
\hline & Granular-fatty \\
\hline & Waxy-granular \\
\hline & Waxy-celullar \\
\hline Blood cast & $\begin{array}{l}\text { (they can be of any subtype, } \\
\text { waxy one prevailing) }\end{array}$ \\
\hline \multirow[t]{3}{*}{ Pigmented } & Haemoglobinic \\
\hline & Myoglobinic \\
\hline & Bilirubinic \\
\hline \multirow[t]{2}{*}{$\begin{array}{l}\text { Containing } \\
\text { microorganisms }\end{array}$} & Bacterial \\
\hline & Candida \\
\hline
\end{tabular}

\section{Hyaline cast}

Hyaline cast (Figure 4) are composed of only THG and they are precursors of all other cylinders (Alatzas et al., 2012) and it casts can exist in various forms, such as compact, bent or wrinkled shapes (Alatzas et al., 2012); Caleffi and Lippi, 2015).

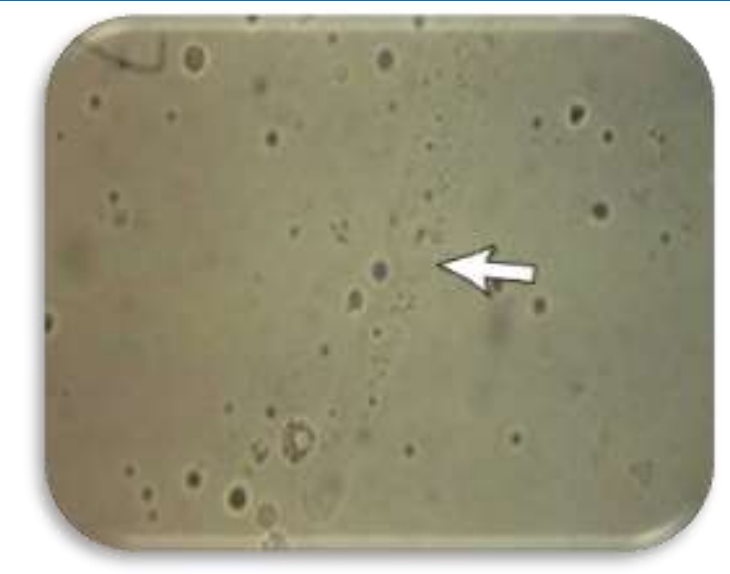

Figure 4. Hyaline cast, unstained preparation, 400x magnification (white arrow)(Chew and Di Bartola, 2004).

Their refractive index is very low, which is why they appear to be very gentle structures that must be observed first at a low magnification in order for them not to be overlooked (Sikirica et al., 2002). In native preparations hyaline casts are pale, colorless, and so it is difficult to see them and they can easily be neglected. Low number of hyaline castings, up to 2 hyaline casts/lpf, can be found in concentrated urine samples of normal dogs and cats (Rizzi et al., 2017). Hyaline casts can be found in healthy animals but only with particular physiological conditions, such as exposure to heavy physical activity, but also with non-renal disorders such as fever, dehydration, acute congestive heart failure (Caleffi and Lippi, 2015).

\section{Erythrocyte casts}

They are made up of Tamm-Horsfall's protein, to which are imbedded intact erythrocytes, of normal morphology (Figure 5.). If the erythrocytes are fully lysed, in the preparation they appear as cylinders of homogeneous structure and characteristic red-brown color, and then represent a blood or hemoglobin cast (Figure 6.). Their presence in the urine is always an indicator of bleeding from the kidney parenchyma. They are not present in the urine of healthy animals (Ringsrud, 2001 ${ }^{\text {a }}$; Sikirica et al., 2002).

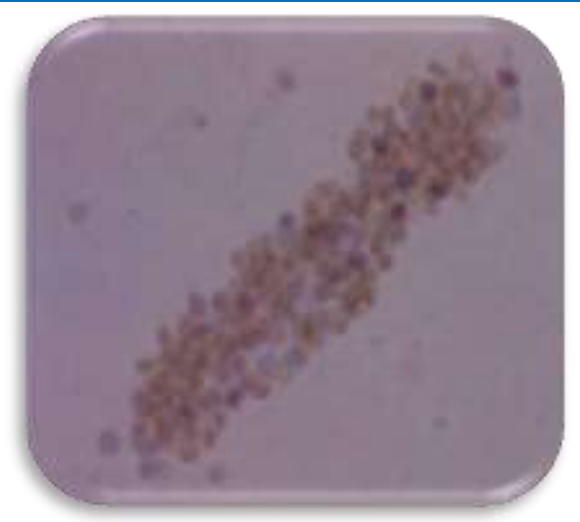

Figure 5. Erythrocyte cast, stained preparation, 400x magnification(Chew and Di Bartola, 2004).

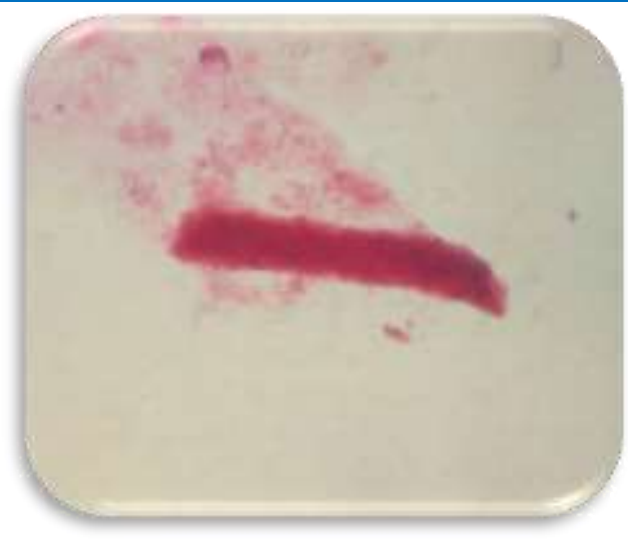

Figure 6. Blood cast (hemoglobin cast or blood cast), stained preparation,400x magnification (Chew and Di Bartola, 2004). 


\section{Leukocyte casts}

They represent mucoprotein casts with incorporated leukocytes, most common being neutrophilic leukocytes (Figure 7). Leukocytes may be intact or degeneratively altered. Their number per cast varies, so casts found can be the ones with many neutrophils or with a few scattered ones throughout the whole cast. They are present in various infectious, chronic and acute kidney diseases, most often in pyelonephritis. They are not present in the urine of healthy animals (Jerkić and Božić, 2012; Sikirica et al., 2002).

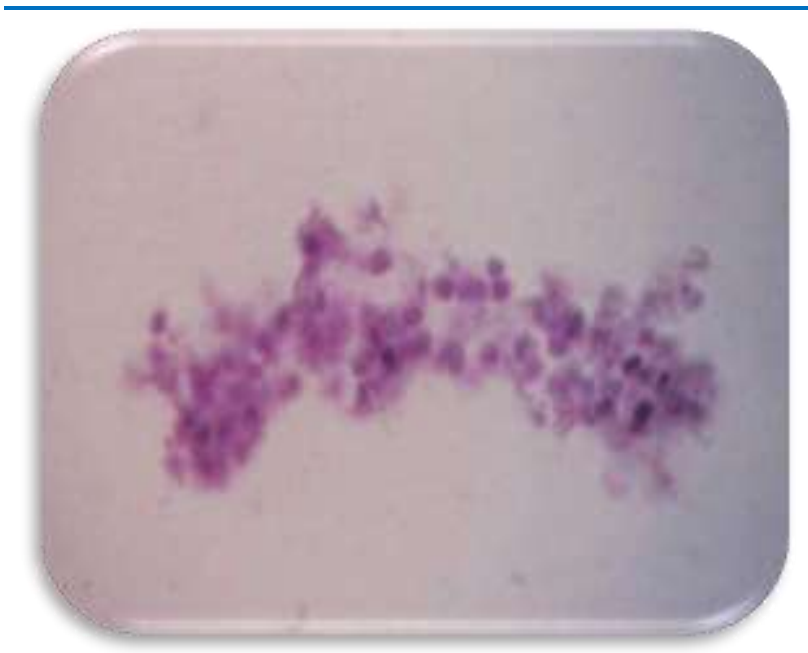

Figure 7. Leukocyte cast, stained preparation, 400x magnification (Chew and Di Bartola, 2004).

\section{Epithelial casts}

They are made out of mucoprotein matrix and kidney tubular epithelial cells (Figure 8.). Cells have very often degenerated and are very difficult to identify, a result from tubular damage. Cellular degeneration changes are manifested in the form of granules, as well as in the appearance of fat drops. Such casts are present in urine in cases where spare kidney tubular epithelial cells can be found. They are not present in the urine of healthy animals (Chew and Di Bartola, 2004; Sikirica et al., 2002).

\section{Granulated casts}

These cylinders consist of granules, which may vary in size, ranging from fine, granulated casts (Figure 9.) to crude, big-granule casts.It has been demonstrated that, in patients with proteinuria, fine granules contain ultrafiltrated proteins that have been reapsorbed through tubular epithelium, whereas roughly granulated casts are noted in patients without an evident proteinuria, likely derived from degeneration of cellular elements, such as leukocytes, epithelial cells etc. The presence of granular casts always indicates a kidney injury (Rutecky et al., 1971; Orita et al., 1977; Caleffi and Lippi, 2015).

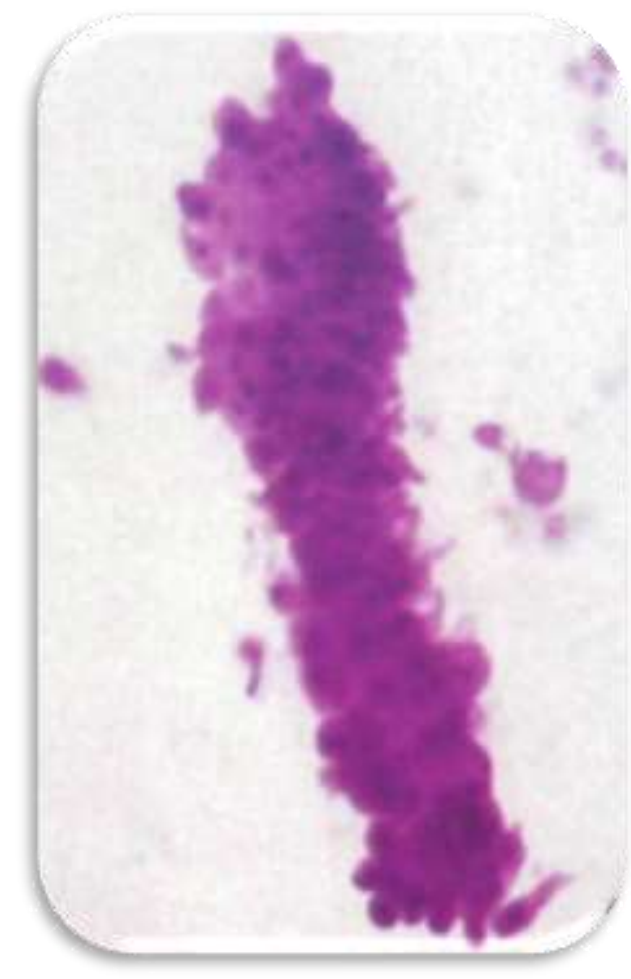

Figure 8. Epithelial cast, stained preparation, 400x magnification (Chew and Di Bartola, 2004).

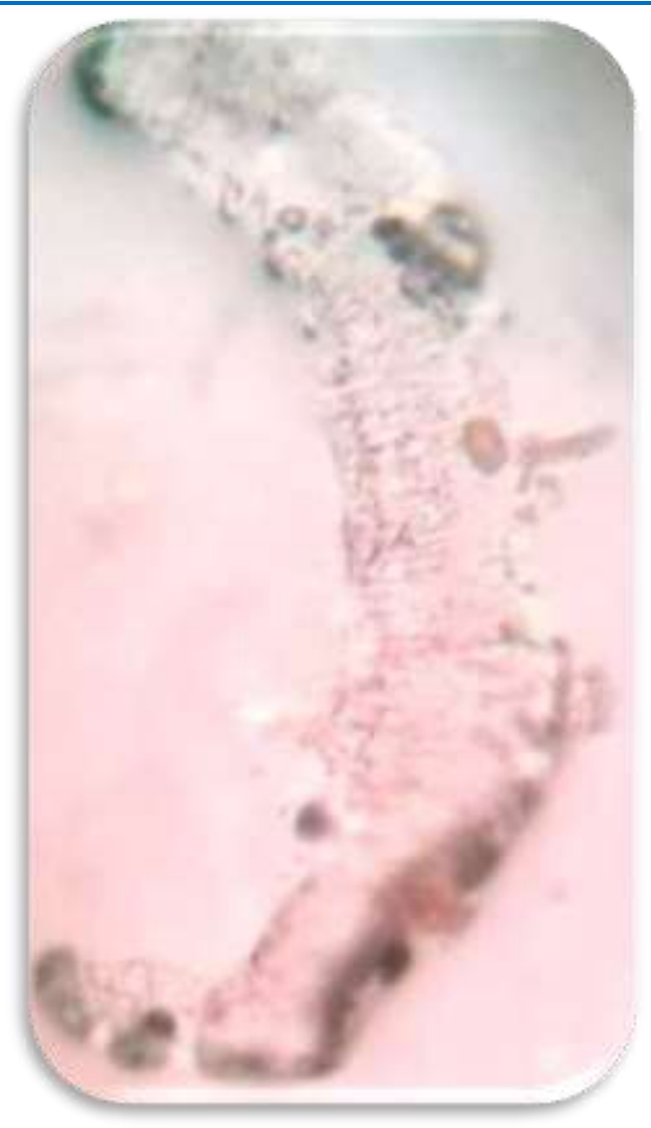

Figure 9. Finely granulated cast, unstained preparation, 400x magnification 


\section{Wide casts}

They can be of any subtype (Figure 10., Table 1.). They are usually formed through collection canals, where normal, high velocity of urine flow is present. In order to form a cast in this part of the nephron, urine flow rate must be seriously reduced. They can also be formed in highly dilated parts of distal tubules. The presence of a large number of wide outflows in the urinary sediment indicates severe kidney disease, but may also indicate recovery as oliguria becomes diuresis in patients with acute renal insufficiency. Most common wide casts are waxy casts (Figure 11.) due to longer intrarenal stoppages (Rizzi et.al., 2017; Chew and Di Bartola, 2004).

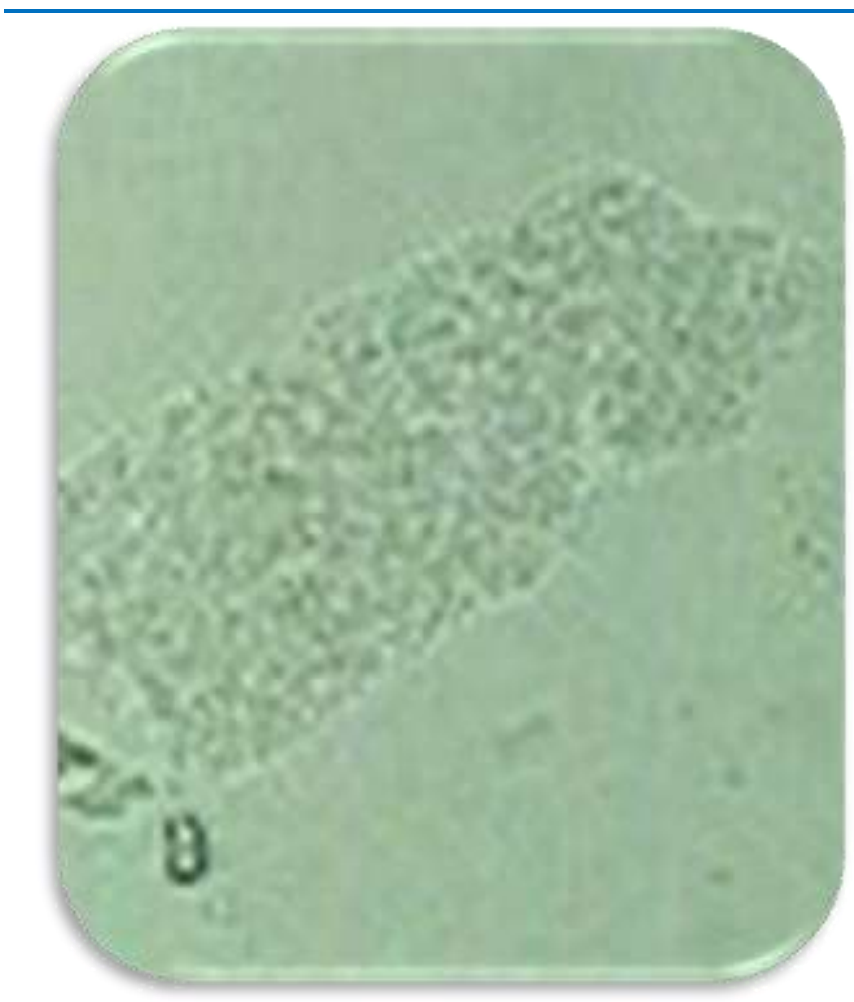

Figure 10. Wide cast, unstained preparation, 400x magnification.

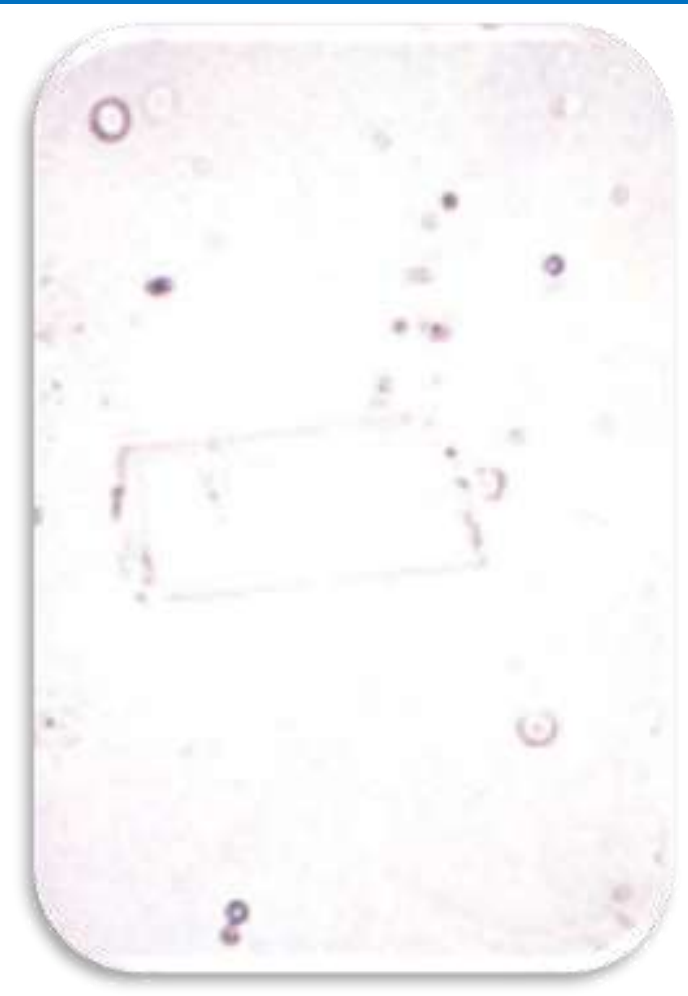

Figure 11. Waxy cast, unstained preparation 560xmagnification (Chew and Di Bartola, 2004).

\section{Waxy casts}

Waxy casts (Figure 11.) are rare in the urine of domestic animals and are considered final stages of degenerated granulated casts (Rizzi et al., 2017). They are present in the urinary sediment in case of a renal function impairment; acute or chronic, renal amyloidosis (Caleffi and Lippi, 2015; Chew and Di Bartola, 2004). Their structure is not clearly known, and recent research suggests that waxy casts in patients with glomerulonephritis do not contain

Tam-Horsal Glucoproteins (THG), and instead contain blood plasma proteins (Spinelli et al., 2013; Chew and Di Bartola, 2004).

\section{Epithelial cells}

Epithelial cells coming from the urinary and genital tract differ greatly in size. Generally, the smallest epithelial cells are formed in kidneys, but other small cells and slightly larger cells also originate from urethra, bladder and proximal urethra. The largest non-neoplastic cells come from the distal part of the urethra, vagina and foreskin. The urine of normal dogs and cats contains several epithelial cells in visible microscopic fields during the urinary sediment analysis.

\section{Squamous epithelium}

Squamous epithelium is the largest cell in the urinary sediment, 40-60 micrometers long in diameter. It originates from the marginal segments of urethra and vagina, which is why it is often present in a small number in the urine sediment. These are polygonal cells, of rounded corners, whose cytoplasm is abundant, and nucleus small and centrally laid (Figures 12. and 13.). 


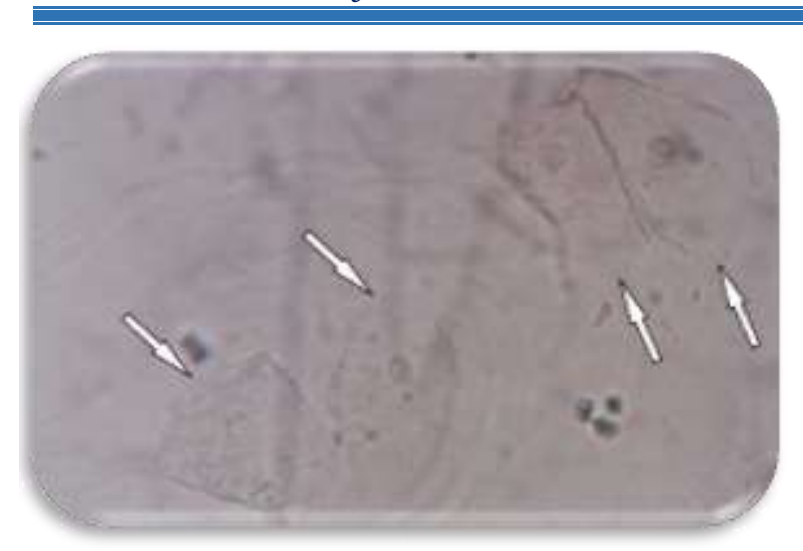

depends on the layer from which it originates, so that if they come from the surface layers, they are usually large polygonal, round or oval mononuclear cells of 30-40 micrometers in diameter, with round or oval nucleus centrally or slightly eccentrically placed. These cells are usually found when there is an infection of the lower parts of the urinary system or some other urological disorder (Figure 14.).

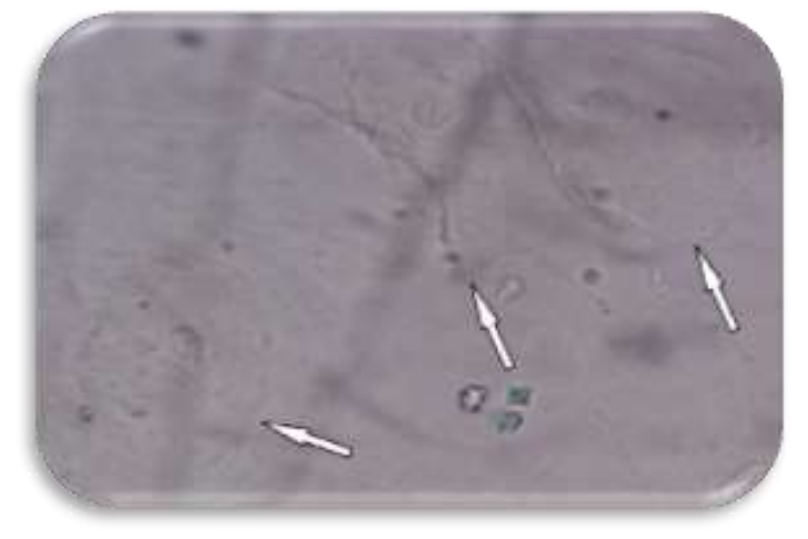

13

Figure 12 and 13. Squamous epithelial cells, unstained preparation, 400x magnification (white arrows).

They come individually, but often in clusters too. If there are enough squamous epithelial cells present in the sediment, with no leukocytes, it suggests that they originate from the lower parts of the urethra, and in most cases represent a contamination due to incorrect shrinkage or poorly applied hygiene of the external genitalia. Such finding has no diagnostic significance, and if a large number of leukocytes is present, vaginal contamination must be excluded to confirm uroinfection. In very rare cases of malignant processes in the lower parts of the urinary system, squamous epithelial cells can be found in the urinary sediment, but then they show changes in structure and shape of the nucleus. In the case of such finding, detailed cytological treatment is required (Ringsrud 2001; Sikirica et al., 2002; Fogazzi, 2010).

\section{Transitional epithelium}

Transitional epithelium is a highly specific epithelium that mostly covers urinary tract pathways, renal pelvis, bladder and proximal part of the urethra. Morphological appearance of the cell

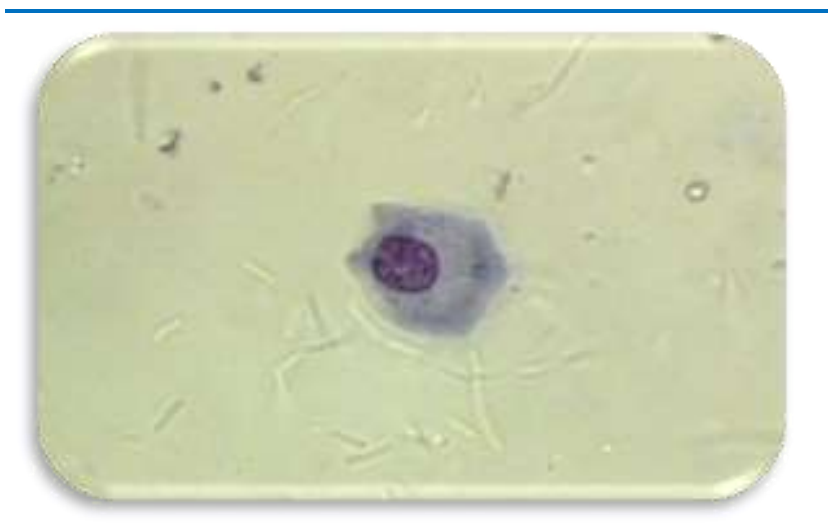

Figure 14. Transitional epithelial cells, stained preparation, 400x magnification (Sikirica et.al., 2002).

Transitional epithelial cells from deeper layers are smaller than cells from the surface layers, but come in many more different shapes. In addition to small round or oval cells, they can appear as though with a "tail", elongated in the form of a baseball bat. Small round cells have a large, centrally laid nucleus with a gentle cytoplasmic ring, and so can easily be mistaken for a tubular epithelium. (Ringsrud, 2001; Sikirica et al., 2002; Fogazzi, 2010).

\section{Kidney tubular epithelium}

Kidney tubular epithelium is a single-layer epithelium that covers nephron, including cells that incase the glomeruli, proximal and distal tubules as well as the collection canals that are therefore present in a large number of different shapes. The kidney-tubular epithelial cells are usually about 13 micrometers long in diameter, round or oval with a large, central or slightly eccentrically placed nucleus, which contains one to two nucleolus. The cells that originate from the collection canals are square shaped. The cells that come from proximal tubules are relatively larger, oval or elongated granulated cells. The appearance of these cells in the urine is associated with acute tubular necrosis. They are also present in cases of fever, various toxic damage, drug damage, poisoning of heavy metals, 
various inflammations, infections, and are also noticed in neoplasms. Their distinction is quite difficult, and they can easily be mistaken for small oval cells from deeper layers of transitional epithelial cells. Tubular cells are usually associated with findings suggesting parenchymal kidney disease such as dysmorphic erythrocytes, casts or lipids, while transitional epithelium is present with leukocytes, isomorphic ("normal") erythrocytes, bacteria or crystals. Their cytoplasm turns red when supravital staining is used, while nucleus turns blue. In patients with abundant proteinuria they may also contain fat droplets. Sometimes, but very rarely, they can be found in healthy urine as a result of epithelial regeneration (Sikirica et al.,2002; Fogazzi, 2010; Ringsrud, 2001)

\section{Lipid cells}

They represent fatty degeneration of the kidneytubular epithelium, and in urine they usually appear as free droplets of fat or tubular epithelial cells saturated with lipids, so-called oval fat bodies. They can also be incorporated in fat cylinders, as well as in cholesterol crystals. They are present in urine if the glomerular basement membrane is damaged, which is why they freely pass through to the urine. As lipids bind to proteins, lipiduria is a typical sign of abundant proteinuria. Lipid cells vary greatly in size, from 2 to 50 micrometers in diameter, in color yellow to light brown, with a very large refractive index. Lipid cells are normally not present in the urine of healthy individuals (Sikirica et al., 2002; Fogazzi, 2010; Ringsrud, 2001).

\section{The causes of infections and infestations}

Bacteria are not present in the urine of healthy individuals, but a smaller number can be found due to contamination, inappropriate urine collection or longer storage on a room temperature. Accurate identification can only be given on the basis of a microbiological test. The fungus are round or oval shaped, homogeneous, without inclusion. They can also appear in the form of hypha. Urine parasites are usually the result of genital or fecal contamination. Contamination artifacts are all elements that come in the urine externally, such as hair, fibers, powders, etc. (Sikirica et al., 2001; Fogazzi, 2010).

\section{CONCLUSION}

Organic urinary sediment analysis is considered to be an important tool for diagnosing kidney diseases. It is necessary to provide better assumptions for successful manual microscopic analysis of urinary sediment; proper sampling of urine, staining of urinary sediment and good knowledge of morphological characteristics of organic components of urinary sediment. Each routine clinical examination of patients should, in addition to other tests, contain urine analysis, including urinary sediment analysis. Unfortunately, this cheap and fast analysis is often omitted in veterinary practice, even though it can be very useful.

\section{ACKNOWLEDGEMENTS}

Authors express their deepest gratitude to their colleagues: Nermin Mujkić, Anja Kovačević and Esma Kadrić, students of the Faculty of Veterinary Medicine of the University of Sarajevo for technical assistance during the preparation of microscopic images of the unstained urinary sediment preparations.

\section{REFERENCES}

Adamama-Moraitou, K.K., Pardali, D., Prassinos. N.N., Menexes, G., Patsikas, M.N., Rallis, T.S. (2017). Evaluation of dogs with macroscopic haematuria: a retrospective study of 162 cases (20032010) New Zealand Veterinary Journal, 65(4), 204 208.

Alatzas, D.G., Mylonakis, M.E., Polyzopoulou, Z.S., Koutinas, A.F. (2012). Urine sediment evaluation in the dog and cat. Journal of the Hellenic Veterinary Medical Society, 63(2),135-146.

Anderlini, R., Manieri, G., Lucchi, G., Raisi, O., Soliera, A.R., Torricelli, F., Varani, M., Trenti, T. (2015). Automated urinalysis with expert review for incidental identification of atypical urothelial cells: An anticipated bladder carcinoma diagnosis, Clinica Chimica Acta; International Journal of Clinical Chemistry, 451(Pt B), 252-256.

Bakan, E., Ozturk, N., Kilic Baygutalp, N., Polat, E., Akpinar, K., Dorman, E., Polat, H., Bakan, N. (2016). Comparison of Cobas 6500 and Iris IQ200 fully-automated urine analyzers to manual urine microscopy Biochemia Medica, 26(3), 635-75.

Bogaert, L., Peeters, B., Billen, J. (2016). Evaluation of a new automated microscopy urinesediment analyser - sediMAX conTRUST $\AA$, Acta Clinica Belgica, 72(2),91-94. Doi: 10.1080/17843286.2016.1249999

Bottini, P.V., Garlipp, C.R., Lauand, J.R., Cioffi, S.G.L., Afaz, S.H.,Prates, R.L. (2005). Glomerular 
and Non-Glomerular Haematuria: Preservation of Urine Sediment. Lab Medicine ,36(10), 647-649.

Caleffi, A., Lippi, G. (2015). Cylindruria.Clin Chem Lab Med, aop. 1-7. Doi: 10.1515/cclm-2015-0480

Caleffi, A., Manoni, F., Alessio, M.G., Ottomano, C., Lippi, G. (2010). Quality in the extra analytical phases of urinalysis. Biochem Med, 20, 179-183.

Chew,D.J., Di Bartola, S.P. (2004). Interpretation of Canine and Feline Urinalysis. Clinical Handbook Series. USA: The Gloyd Group, Inc.Wilmington, Delaware.

Chew, D.J., Di Bartola, S.P., Schenck, P.A. (2011). Canine and Feline Nephrology and Urology. $2^{\text {nd }}$ ed. USA: Elsevier Saunders, St. Louis. Clinical and Laboratory Standard Institute (ex NCCLS) (2009). GP16- A3-Urinalysis; approved guideline, 3rd ed. Wayne, PA: CLSI, Comparison of Cobas 6500 and Iris IQ200 fully-automated urine analyzers to manual urine microscopy Biochemia Medica, 26(3),635-75.

Cook, A.K., Cowgill, L.D. (1996). Clinical and pathological features of protein-losing glomerular disease in the dog: A review of 137 cases (19851992). Journal of the American Animal Hospital Association, 32(4), 313-322.

Eggensperger, D., Schweitzer, S., Ferriol, E., O' Dowd, G., Light, J.A. (1988). The utility of cytodiagnostic urinalysis for monitoring renal allograft injury. A clinicopathological analysis of 87 patients and over 1000 urine specimens. Am J Nephrol, 8 (1), 27-34.

European Confederation of Laboratory Medicine. (2000). European urinalysis guidelines. Scand J Clin Lab Invest Suppl, 231, 1-86.

Fogazzi, G, B. (2010). The urinary sediment. An integrated view, $3^{\text {rd }}$ ed. Milan: Masson Elsevier.

Forrester, S. (2004). Diagnostic approach to hematuria in dogs and cats. Veterinary Clinics of North America, Small Animal Practice, 34, 849e867.

Grossfeld, G.D., Litwin, M.S., Wolf, J.S., Hricak, H., Schuler, C.L., Agerter, D.C., Carroll, P.R. (2001). Evaluation of asymptomatic microscopic hematuria in adults: The American Urological Association best practice policy - part I: definition, detection, prevalence, and etiology. Urology, 57, 599-603.

Jerkić, M., Božić, T. (2012). Poremećaj funkcije bubrega. U: Božić T (ur.), Patološka fiziologija domaćih životinja. Univerzitetski udžbenik, 2. izdanje. Naučna KMD, Beograd, Srbija, 463-490.

Kardum-Skelin, I. (2004). Citologija mokraće. U: Flegar- Meštrić Z (ur.), Kliničko-biokemijska korelacija rezultata kvalitativne analize mokraće.Medicinska naklada, Zagreb, Hrvatska, 81106.

Knežević, G., Parigros, K., Križaj, B., Anić, V., Pažur, M., Jelić-Puškarić, B., Šušterčić, D., KardumSkelin, I. (2011). Erythrocyte morphology in urine determined by light microscopy in patients with bladder cancer.Acta med Croatica, 65 (Supl. 1), 121125.

Kouri, T., Fogazzi, G., Gant, V., Hallander, H., Hofmann, W., Guder, W.G. (2000). European urinalysis guidelines. ECLM - European Urinalysis Group. Scand J Clin LabInvest 60, Suppl 23, 11-96.

Manoni, F., Valverde, S., Caleffi, A., Alessio, M.G., Silvestri, M.G., De Rosa, R., et al. (2008). Stability of common analytes and urine particles stored at room temperature before automated analysis. RIMeL - IJLAM 4, 192-8.

Nakamura, K., Kasraeian, A., Iczkowski, K.A., Chang, M., Pendleton, J., Anai, S., Rosser, C.J. (2009). Utility of serial urinary cytology in the initia evaluation of the patient with microscopic hematuria. BMC Urol, 9, 12. doi: 10.1186/1471-2490-9-12.

Nash, A., Wright, N., Spencer, A., Thompson, H., Fisher, E. (1979). Membranous nephropathy in the cat: a clinical and pathological study. Veterinary Record 105, 71-77.

Orita.Y., Imai, N., Ueda, N., Aoki, K., Sugimoto, K., Ando, A., et al. (1977). Immunofluorescent studies of urinary casts. Nephron, 19, 19-25.

Ostović, K.T. (2015). Cytologic urinalysis with hematuria and glomerulonephritis. Paediatr Croat, 59 (Supl1),66-71.

Oyaert, M., Delanghe, J. (2018). Progress in Automated Urinalysis, Ann Lab Med, 39,15-22.

Reine, N.J., Langston, C.E. (2005). Urinalysis Interpretation: How to squeeze out the maximum information from a small sample. Clin Tech Small Anim Pract, 20, 2-10.

Ringsrud, K.M. (2001). Casts in the urine sediment. Lab Med, 32(4), 191-3.

Ringsrud, K.M. (2001). Cells in the urine sediment. $L a b$ Med, 32(3), 153-5.

Rizzi, T.E., Valenciano, A., Bowles, M., Cowell, R., Tyler, R., De Nicola, D.B. (2017). Atlas of Canine and Feline Urinalysis. 1st ed. USA: John Wiley \& Sons, Inc. Published. doi:10.1002/9781119365693.ch4

Rutecky, G.J., Goldsmith, C., Schreiner, G.E. (1971). Characterization of proteins in urinary casts. $N$ Engl $J$ Med, 284, 1049-52.

Sharma, S., Ksheersagar, P., Sharma, P. (2009). Diagnosis and treatment of bladder cancer. Am Fam Physician, 80 (Suppl. 7), 717-2.

Sikirica, M., Bobetić-Vranić, T., FlegarMeštrić, Z., Kardum-Skelin, I., Juretić, D. (2002). Standardized analysis of supravitally stained urine sediment. Biochemia Medica, 12(3-4), 57-72. 
Spinelli, D., Consonni, D., Garigali, G., Fogazzi, G.B. (2013). Waxy casts in the urinary sediment of patients with different types of glomerular diseases: results of a prospective study. Clin Chim Acta, 424, 47-52.

Swenson, C.L., Boisvert, A.M., Kruger, J.M., Gibbons-Burgener, S.N. (2004). Evaluation of modified Wright-staining of urine sediment as a method for accurate detection of bacteriuria in dogs. $J$ Am Vet Med Assoc, 224, 1282-9.

White, J.D., Norris, J.M., Bosward, K.L., Fleay, R., Malik, R. (2008). Persistent haematuria and proteinuria due to glomerular disease in related Abyssinian cats. Journal of Feline Medicine and Surgery, 10, 219-229. doi:10.1016/j.jfms.2007.11.007 